\title{
Applications of Virtual Reality Technology on Cultivation of Undergraduates in Agronomy Specialty
}

\author{
Yihong Hu *, Wenshuai Zeng, Chenzhong Jin, Xuejiao Zhang, Yong Chen \\ Key Laboratory of Harmless Application of Pesticide in Hunan Higher Education \\ Hunan University of Humanities, Science and Technology \\ Loudi 417000, Hunan, China \\ huyhongwangyi@163.com
}

\begin{abstract}
The cultivations of experimental and practical abilities are the most important aspects during the education of undergraduate students in the agronomy specialty. But some experiments and off-campus practical trainings are restricted by the real conditions, and actually the undergraduate students cannot be trained well. In recent years, the virtual reality (VR) technology has been gradually more and more widely used in the experiment te aching and practical training in high education. In this paper, we introduced the advantages of the VR technology in the experiment teaching and practical training in the agronomy specialty, and introduced the experiences we gained during our teaching by using the VR technology. These experiences will be helpful references for the other teaching institutions.
\end{abstract}

Keywords—virtual reality; agronomy specialty; experiment teaching; practical training

\section{INTRODUCTION}

Agriculture is the so-called "basic industry" for the national economical development in our country. In the recent years, the agricultural technologies have been developed rapidly, and more and more new technologies and facilities have been applied to the agricultural areas rapidly. These areas in agriculture mainly include the breeding, the cropping system, the plant protecting, the facility planting, the agricultural information, etc., showing an ever-developing trend of multidisciplinary intersections [1-3]. In order to cultivate qualified talents for the local economical construction, our university founded the agronomy specialty in 2012, which was the first undergraduate specialty in the agricultural areas of Hunan University of Humanities, Science and Technology.

The agronomy specialty emphasizes on cultivating the comprehensive abilities of undergraduate students especially on the abilities of application and innovation, and then training the practical and experimental abilities becomes particularly important in teaching. Based on this specialty, we have successfully applied for a series of scientific research and teaching platforms including a provincial key construction discipline "plant protecting", a provincial key laboratory "Key Laboratory of Harmless Application of Pesticide”, a provincial collaborative innovation center "Hunan Provincial Collaborative Innovation Center for Field Weeds Control”, and

This research was financially supported by Innovation Base for Postgraduates Cultivation of Hunan Province (2261602) and Research Project of Teaching Reform of Degree and Graduate Education in Hunan (JG2016B106). a provincial virtual reality (VR) teaching and demonstration center "Provincial VR Teaching and Demonstration Center for Agronomy and Biotechnology". With these years' construction on these platforms, we have not only achieved a series of results in the scientific research, but also made encouraging achievements in the undergraduate teaching of the agronomy specialty. For example, a VR show room and a multi-media classroom have been built in the VR demonstration center, nine sets of VR teaching software have been developed and already put into use for the experiment teaching and practice training up to now, and seven more sets of software are in process of development. Since all of these teaching resources are based on an open policy, these teaching resources can be used conveniently both in class and after class by the teachers and the undergraduate students, and these resources can also be shared and utilized by the teachers and students in other universities.

The VR technology in teaching has been developed rapidly in recent years. It can effectively overcome the obstacles in the traditional teaching mode and can simulate the procedures which are unrepeatable or difficult to repeat in reality, and it can also resolve the high costs during the ordinary experiment teaching [4-5], whereas in the traditional experiment teaching, the students can only do simply experiments within limited time in the laboratory and can not re-adjust the experimental parameters repeatedly as they want in order to further understand the experimental principles. Furthermore, some dangerous or time-consuming experiments can not be operated and finished in the real laboratories. On the other hand, in the practical training, the students can not understand the key technologies in most cases owing to the fact that the enterprises always want to keep their technique secrets in their areas and are not willing to arrange the student trainees to the key positions. All of these factors seriously limited the realization of the goal to cultivate qualified talents with vocational abilities and innovative abilities for the local economical construction. On the contrary, the VR technology has a very good humancomputer interaction and it can exhibit vividly the abundant teaching contents in computer without the limitation of time and space, efficiently fill in the gaps existing in front of the traditional experiment teaching and practice teaching, and will significantly promote the techniques of the undergraduate 
students [6-8]. In this paper, we introduced the experiences during the experiment teaching and practical training by using the VR technology on the cultivation of the undergraduate students in the agronomy specialty, and hope to provide some helpful some references for other universities.

\section{ApPlicAtions OF VR TeChNOLOGy IN EXPERIMENT TEACHING}

\section{A. Experiment Teaching with Combination of Virtual and Reality to Promote Teaching Effects}

The combination of virtual and reality can extend the experiment items and promote the experiment teaching effects [9]. For example, the experiments of biological detection and agricultural residue determination need a lot of precise instruments such as gas chromatography (GC), high efficiency liquid chromatography (HPLC), mass spectrometer (ms), capillary electrophoresis instrument, etc. As usual, the undergraduate students can only learn the operational principles of these precise instruments in class, but they have few chances to operate these precise instruments by themselves owing to the fact that these instruments are sophisticated and the consumptive chemicals and reagents are very expensive. Generally, these complicated instruments can only be operated by assigned teachers or postgraduate students in most universities.

According to these circumstances, our center developed a set of virtual simulation experiments of biological and agronomic testing and analysis instruments including polymerase chain reaction (PCR) system, GC, HPLC, ms, fermentation tank, capillary electrophoresis instrument, etc (Table I). All of the VR experiments are with high simulation to the real instruments, and the students can interacted with these virtual instruments by modifying their parameters to deepen their understandings on the principles of the instruments, and then they will be more familiar with the operations of the instruments. After trained with the VR programs first, the students will be easier to master the operation steps of the real instruments during the later learning or scientific research. Through these VR experimental trainings, we found that a part of the undergraduate students could operate these instruments independently during their graduation thesis stages.

TABLE I. VIRTUAL SIMULATION EXPERIMENTS OF BIOLOGICAL AND AGRONOMIC TEST ING AND ANALYSIS INST RUMENT S OF HUNAN UNIVERSITY OF HUMANITIES, SCIENCE AND TECHNOLOGY

\begin{tabular}{|c|c|c|c|}
\hline No. & Experiment items & $\begin{array}{c}\text { Experiment } \\
\text { type }\end{array}$ & Supported instruments \\
\hline 1 & $\begin{array}{c}\text { Atomic absorption } \\
\text { spectrometer } \\
\text { virtual simulation }\end{array}$ & Comprehensive & $\begin{array}{c}\text { Spectrum instrument SP- } \\
\text { 3520AA atomic absorption } \\
\text { spectrometer, graphite oven, } \\
\text { and acetylene cylinder }\end{array}$ \\
\hline 2 & $\begin{array}{c}\text { Capillary } \\
\text { electrophoresis } \\
\text { virtual simulation }\end{array}$ & Comprehensive & $\begin{array}{c}\text { Beckman P/ACE MDQ } \\
\text { capillary electrophoresis } \\
\text { apparatus and accessorial } \\
\text { equipments }\end{array}$ \\
\hline
\end{tabular}

\begin{tabular}{|c|c|l|c|}
\hline \multicolumn{2}{|c|}{ Cont. to TABLE I } \\
\hline 3 & $\begin{array}{c}\text { Fluorogenic } \\
\text { quantitative PCR } \\
\text { virtual simulation }\end{array}$ & Comprehensive & $\begin{array}{c}\text { Thermo Fisher PikoReal } \\
\text { fluorogenic quantitative PCR } \\
\text { and the additional } \\
\text { instruments including } \\
\text { centrifuge, electrophores is } \\
\text { apparatus, and analysis } \\
\text { software }\end{array}$ \\
\hline 4 & $\begin{array}{c}\text { Chromatography } \\
\text { virtual simulation }\end{array}$ & Comprehensive & $\begin{array}{c}\text { HPL-ms, Shimadzu 8030 } \\
\text { GC-ms, Shimadzu LC-10, } \\
\text { Shimadzu GC-14C, and } \\
\text { analysis software }\end{array}$ \\
\hline 5 & $\begin{array}{c}\text { Counter-current } \\
\text { chromatography } \\
\text { virtual simulation }\end{array}$ & Comprehensive & $\begin{array}{c}\text { Tauto Biotech TBA-300A } \\
\text { counter-current } \\
\text { chromatography, and } \\
\text { analysis software }\end{array}$ \\
\hline 6 & $\begin{array}{c}\text { Fermentation } \\
\text { virtual simulation }\end{array}$ & Innovative & $\begin{array}{c}\text { Shanghai Shiyuan SY-3020 } \\
\text { fermentation tank, and UV } \\
\text { sterile operating table }\end{array}$ \\
\hline
\end{tabular}

B. Realizing those experiments which can not be operated in realty

In the agronomy specialty teaching, some experiments are very difficult to operate in laboratories. Thus, the effects of class teaching are often unsatisfactory. For example, in the facility agriculture course, the teachers can only introduce the structure of greenhouse and teach students how to design it in class. It is difficult for students to master how to design and build a real greenhouse and how to disassemble the greenhouse accordingly. Even when in a real greenhouse, the teachers can only depict the structure and function of the greenhouse. As usually, it is impossible to assemble and disassemble the real greenhouse on site because the work is dangerous, timeconsuming, and costly. By using the VR technology, our center developed a virtual simulation program for students to assemble and disassemble greenhouse. Then the students can design the greenhouse in a simulation circumstance and finally promote their practical abilities.

\section{APPLICATIONS OF VR TECHNOLOGY IN PRACTICAL TEACHING AND TRAINING}

\section{A. Applications of VR technology in field practical teaching}

In the practical training of undergraduate students in agronomy, the training is often limited both with the agricultural farming periods and the growth cycles of the main crops. Thus, it is very difficult to arrange a suitable time period for undergraduate students in the agronomy specialty to attend the training. In the rice planting areas of Hunan Province in China, when the students need to practice in field, it is just the period that the students should study on campus. In view of this situation, we design a serial of crop cultivation VR simulation software, and the students can be trained with these VR experiments initially. After trained by the VR experiments first, they will adapt the real field circumstance very soon and save a lot of time during the real practical training. 


\section{B. Applications of VR technology in factory practical teaching}

The factory practical training is a very important ring for the undergraduate education in the agronomy specialty, and it has been puzzling the universities and teachers for quite a long time. As for the agricultural processing enterprises, they are becoming more and more of internationalization, and their products and laboratories should be qualified for many standards including the Good Manufacturing Practice (GMP), the National Quality Standard, the Good Laboratory Practice (GLP), and the International Standardization Organization (ISO) Certification System. As usual, it is impossible for these enterprises to accept too many students to practice in their factories because of the strict products standards and laboratory standards. Furthermore, these enterprises often own their core technologies and know-how, and they always want to keep the technical secrets to be one step ahead of the other enterprises in the markets. They are not willing to accept students to practice in the key positions.

Agricultural processing is a key direction in agronomy, and the practical trainings in factories are very important for students to promote their vocational skills. Our university has been cooperated with Hunan Wuxing Biological Technology Co. for many years and established a practical teaching base in the factory since 2015. This factory is located in Loudi City of Hunan Province and is one of the largest factories to produce chondroitin sulfate material in the world. It is a new high-tech enterprise and its products are welcome and sold very well to the European and North American markets. Strictly required with the product processing standards, the factory is not willing to enroll too many trainees of students into their factory to work in post. In 2017, our center began to joint-design a VR simulation experiment with this company according to the real factory processing steps including the whole processes of chondroitin sulfate production such as hydrolysis of bovine cartilages, super membrane filtering, tubular centrifugation, ion-exchange column chromatography, oxidative dehydrogenation, alcohol precipitation, spray drying, and packing. And we also designed the VR program covering the by-products processing including the productions of amino acid powder and skeleton powder. The students can set different parameters to adjust each step of every procedure in a virtual circumstance, and use the virtual simulation program to get to know the whole process of chondroitin sulfate production and its by-products production. At the same time, the students also can switch the screen to the factory to observe the real production scenarios remotely and can discuss problem in a forum embedded in the virtual software.

\section{Carrying out vocational technical trainings by using VR technology}

The training goal of the agronomy specialty is to cultivate the qualified agricultural talents for the local economical construction, especially emphasizing on culturing the students' abilities of practice and vocation. Plant protection is the characteristic of the agronomy specialty in our university, and it is also supported by the provincial key laboratory and the provincial key discipline in our university. Although the students are trained well both in the theory learning and experiment training, their vocational skills still leave much room to be desired.

The large scale pest prevention and management and the large scale agricultural production are the common trends in the southern parts of China in the near future. According to this point of view, our center bought one single-engine unmanned agricultural aircraft in 2017, which can spray not only farm chemicals such as herbicides and insecticides but also crop seeds. At the same time, we developed a VR simulation program to train drivers of this aircraft. The students can be trained with the VR program for several weeks first, and then they begin to operate the real unmanned agricultural aircraft in fields under the guidance of teachers. Up to now, four teachers have been well trained and are qualified and familiar with the operation and maintaining of the aircraft. And this system will be put into use for training the students in the agronomy specialty of 2017 grade.

\section{SUMMARY}

In this paper, we introduced the applications of VR technology in the experiment teaching and the practical training for undergraduate students in the agronomy specialty in Hunan University of Humanities, Science and Technology. By use of the VR technology, we promoted the effects of experiment teaching, realized operating the experiments which can not be done in the real circumstances, and developed the vocational technical trainings for students. We hope that these experiences will be helpful references for the other teaching institutions.

\section{REFERENCES}

[1] X. Xiao, "Importance of physics agricultural technology to modernized agriculture in China and its application,” Journal of Anhui Agriculture Science, vol. 38, pp. 17992-17993, 2010.

[2] Y. Zhang, P. Wang, L. Wang, G. Sun, J. Zhao, H. Zhang, and N. Du, "The influence of facility agriculture production on phthalate esters distribution in black soils of northeast China," Science of the Total Environment, vol. 506-507, pp. 118-125, 2015.

[3] Y. Li, J. Wang, L. Qiu, Y. Ma, X. Li, and J. Wan, “Crop molecular breeding in China: current status and perspectives," Acta Agromomica Sinica, vol. 36, pp. 1425-1430, 2010.

[4] Y. Wu, W. Zhang, and G. Li, "Functions of virtual reality technology in cultivation of students in biopharmaceuticals specialty," Strait Pharmaceutical Journal, vol. 28, pp. 257-258, 2016.

[5] J. Guo, X. Li, and W. Liu, “Application of virtual simulation experiment in experimental teaching of animal biochemistry,” Animal Husbandry and Feed Science, vol. 38, pp. 81-83, 2017.

[6] P. Li, C. Mao, and J. Xu, "Construction of the national virtual simulation experiment teaching centers, improving the experimental teaching informatization in higher education," Research and Exploration in Laboratory, vol. 32-11, pp. 5-8, 2013.

[7] J. Zhang, and L. Zhang, "Study on application of virtual simulation in experimental teaching,” Experimental Technology and Management, vol. 30, 101-104, 2013.

[8] Y. Liu, and L. Yu, "Exploration on construction idea and development mode of virtual simulation experimental teaching center,” Experimental Technology and Management, vol. 33, 108-114, 2016.

[9] Y. Liu, Y. Wu, L. Su, and L. Liu, "Construction of virtual simulation experimental teaching system of life science and technology," Experimental Technology and Management, vol. 32, 120-123, 2015. 